\title{
Effects of Eight-week Pilates Training on Elderly People's Dynamic and Static Balance Abilities Jung-Hyun Choi, PT, $\mathrm{PhD}^{\dagger}$ \\ Department of Physical therapy, Namseoul University
}

Received: July 31, 2014 / Revised: August 8, 2014 / Accepted: August 22, 2014

(c) 2014 J Korean Soc Phys Med

\section{| Abstract}

PURPOSE: Improving elderly people's balance ability through pilates which may be easily applied in ordinary life is considered an important intervention method for elderly people. Therefore, this study examines the effects of pilates training on elderly people's static and dynamic balance abilities and provides clinical data to improve this ability.

METHODS: The pilates program was applied to 19 elderly subjects three times per week for 8 weeks. Their training level took into consideration their age and was set so that the rating scales of perceived exertion became 13 to 14 . Prior to the initiation of the experiment, the subjects had an adaptation period in order to practice the order and motions of pilates. After the adaptation period, the subjects received training. The program was conducted three times per week, for eight weeks. Their dynamic balance ability was observed through the timed up and go (TUG) test and tandem walk test (TWT), and their static balance ability was evaluated by the center of pressure (COP) area, medial-lateral displacement, and anterior-posterior displacement.

†Corresponding Author : vchoi77@empal.com

This is an Open Access article distributed under the terms of the Creative Commons Attribution Non-Commercial License (http://creativecommons.org/licenses/by-nc/3.0) which permits unrestricted non-commercial use, distribution, and reproduction in any medium, provided the original work is properly cited.
RESULTS: The results of the TUG test and TWT and evaluations of the COP area and medial-lateral displacement were significantly different after the pilates exercise program compared to those before the program began.

CONCLUSION: The results show that an 8-week pilates exercise program is an effective method to increase elderly people's static and dynamic balance abilities. In addition, the application result of the pilates exercise program will provide useful information for future research on elderly people's balance ability.

Key Words: Pialtes, Elderly people, Balance

\section{INTRODUCTION}

The progress of aging occurs throughout the body, including the internal organs, muscles, and nervous system, and the changes involved trigger discomfort in performing daily activities(Jessup et al, 2003). In elderly people who do not exercise, muscle atrophy or decreased bone density is promoted and their balance ability is reduced due to regressive changes from aging(Tideiksaar, 1996). For balance, information provided by the visual system, the vestibular system, and the somatosensory system should be integrated by the brain for specific joints and muscles 
in order to adjust their timing, sequence, and strength and create voluntary or responsive movements(Shumway-Cook and Wollacott, 2011). However, when postural movements are restricted and postural control is reduced due to aging, the risk of falls increases(Gauchard et al., 2003). Noll(2013) found that muscle strengthening exercise, flexibility training, aerobic exercise, and other diverse types of exercises, including gait, are useful to maintain or increase elderly people's muscle strength and improve their balance and gait velocity. Low-level aerobic exercise has been found to be effective in enhancing the muscle strength, flexibility, and balance of elderly people staying at home (Shumway-Cook et al., 1977), and postural control ability significantly improved in a group taking part in a balance exercise program for 6 months(Carmeli et al, 2003).

The ability to maintain balance and stability is a necessity for active humans. Balance is largely divided into static balance and dynamic balance. Static balance refers to the ability to maintain balance during postural maintenance by keeping the center of gravity within the base of support. Dynamic balance is the ability to maintain balance when the body moves and to maintain a desired posture by keeping the center of gravity within the base of support during body movement(Shumway-Cook and Wollacott, 2011).

Pilates, created by Joseph H. Pilates in Germany around 1920 , is a system of performing aerobic and muscle strengthening exercises together. It is known to effect body shape correction through improvements in muscular flexibility and joint range of motion(Anderson and Spector, 2000; Lee and Rachel, 2005). In pilates, abdominal muscles, muscles surrounding the spine, gluteal muscles, and muscles surrounding the pelvis are considered to be "core," and these muscles engage in the functional stability of the trunk(Aladro-Gonzalvo et al, 2012). When the core is strengthened, stability of the waist and trunk and stability under dynamic situations may be enhanced(ShumwayCook and Wollacott, 2011). Kloubec (2010) noted that application of pilates exercise twice per week for 12 weeks significantly ameliorated muscle endurance, flexibility, balance ability, and postural control(Kloubec, 2010). Queiroz et al. (2010) observed changes in activity of the external oblique abdominal muscle and the gluteus maximus muscle while performing pilates exercise in a quadruped position and reported that activity of the two muscles increased with improved balance ability; this improvement was suggested as having a positive effect in preventing a fall.

Studies have examined lower limb strengthening training, ankle strategy exercises, and proprioceptive motor control programs in order to improve elderly people's balance ability(Shumway-Cook et al., 1997; Karlsson et al., 2013; Gras et al., 2004), but research on improving balance ability through pilates has been lacking. Enhancing elderly people's balance ability through pilates, which can be easily applied in ordinary life, is considered an important intervention for elderly people. Accordingly, this study examines the effects of pilates exercise on elderly people's static and dynamic balance abilities and provides clinical data for enhancing this ability.

\section{METHODS}

This study measured static and dynamic balance abilities of 19 elderly subjects after applying a 8-week pliates training program to them. The study methods are as follows.

\section{Research subjects}

The subjects of this study were 19 elderly people residing in a long-term care hospital located in Yongin City. Table 1 shows their physical characteristics. The inclusion criteria for selection were as follows:

A. Those who have not fallen in the past 1 year;

B. Those who can independently walk $5 \mathrm{~m}$ or longer without taking a rest; 
Table 2. Pilates program

\begin{tabular}{|c|c|c|}
\hline Step & \multicolumn{2}{|c|}{ Program Content } \\
\hline $\begin{array}{l}\text { Warm up exercise } \\
\text { (15 minutes) }\end{array}$ & $\begin{array}{l}\text { 1. Breathing: 2reps-2sets } \\
\text { 3. The bridge: } 2 \text { reps-2sets } \\
\text { 5. Quadruped: } 3 \text { reps-2sets }\end{array}$ & $\begin{array}{l}\text { 2. Dead bug: 2reps-2sets } \\
\text { 4. Roll-up: 3reps-2sets } \\
\text { 6. Prone press: 3reps-2sets }\end{array}$ \\
\hline $\begin{array}{l}\text { Pilates exercise } \\
\text { (40 minutes) }\end{array}$ & $\begin{array}{l}\text { 1. Hundred: 4reps-2sets } \\
\text { 3. The rollover: 2reps-2sets } \\
\text { 5. Single-straight-leg stretch: 2reps-5sets } \\
\text { 7. Swan: 2reps-2sets }\end{array}$ & $\begin{array}{l}\text { 2. One-leg stretch: 2reps-3sets } \\
\text { 4. The roll-up advanced: } 2 \text { reps-4sets } \\
\text { 6. The seal: 4reps-2sets } \\
\text { 8. Single-leg kick: 2reps-2sets }\end{array}$ \\
\hline $\begin{array}{l}\text { Cool down exercise } \\
\text { (15 minutes })\end{array}$ & $\begin{array}{l}\text { 1. Side kick: 2reps-2sets } \\
\text { 3. Spine stretch: 2reps-4sets } \\
\text { 5. Standing balance with parallel hip flexion: } \\
\text { 2reps-2sets }\end{array}$ & $\begin{array}{l}\text { 2. Mermaid: } 2 \text { reps-2sets } \\
\text { 4. Spine twist: } 2 \text { reps- } 4 \text { sets } \\
\text { 6. Standing balance with parallel hip extension: } \\
\text { 4reps-2sets }\end{array}$ \\
\hline
\end{tabular}

C. Those who have no pain that may affect gait;

D. Those who do not take medication that may affect balance ability;

E. Those who have no neurological or musculoskeletal abnormality that could trigger imbalance and a fall;

F. Those whose Korean version of the mini-mental state examination score is 20 points or higher;

G. Those who have no severe visual or somatosensory damage that may affect the experiment.

Table 1. General features of the research subjects

\begin{tabular}{cc}
\hline Characteristic & Subjects $(\mathrm{n}=21)$ \\
\hline Age $(\mathrm{y})$ & $63.53 \pm 2.41$ \\
Height $(\mathrm{cm})$ & $159.27 \pm 8.42$ \\
Weight $(\mathrm{kg})$ & $59.41 \pm 10.83$ \\
MMSE & $24.31 \pm 2.28$ \\
\hline
\end{tabular}

\section{Measurement Tools and Methods}

(1) Pilates exercise program

The pilates training level was set so that the rating scales of perceived exertion were 13 to 14 in consideration that the subjects were elderly people. An adaptation period was incorporated so subjects could learn the motions and their order before the initiation of the experiment. Training was conducted after the adaptation period ended. The pilates program was applied three times per week for 8 weeks. The methods by Emery et al.(2010) and Park et al.(2011) were modified and used for the training program. Table 2 displays the specific content of the pilates exercise program.

(2) Timed up and go (TUG) test

The TUG test is a testing method to swiftly measure basic mobility and balance; it measures the time taken to walk $3 \mathrm{~m}$ from a sitting position, return, and sit in the chair again(Podsiadlo and Richardson, 1991). Prior to measurement, the testing method was explained to the subjects and the researcher demonstrated how to perform it. Measurement was taken after exercises were performed two to three times.

(3) Tandem walk test (TWT)

The TWT is a method to measure dynamic balance ability and a tool used to measure balanced gait and lower limb mobility(Mallinson and Longridge, 2008). Prior to measurement, the testing method was explained to the subjects, and the researcher demonstrated how to perform it. Measurement was taken after exercises were performed two to three times. The subjects walked a 3-m marked straight line while touching the heel of one foot to the toe of the other with each step as fast as possible. When 
a start signal was given, a stopwatch was started from zero. The time during which the subjects broke from the line or lost balance was also included in the measured time. The faster record of two measurements was used for analysis.

(4) Center of pressure (COP) area, medial-lateral displacement, and anterior-posterior displacement

Measurement of COP values with standing quietly was carried out with BT4(Hur lap Inc.). COP excursion was tested using a four-channel portable force platform that was calibrated prior to testing; channels were checked before each test. Participants were instructed to look straight ahead and stand as still as possible with arms hanging down. The foot position was standardized to a $2 \mathrm{~cm}$ heel-to-heel distance and an angle of $30^{\circ}$ between the feet. The participants stood still for at least $5 \mathrm{sec}$ (pre-phase) before the measurement. After the pre-phase, the COP was measured for the next $60 \mathrm{sec}$; signals were sampled at $200 \mathrm{~Hz}$ and filtered with a low-pass digital filter at a 7.8-Hz cut-off frequency prior to sampling. Signals were filtered with two low-pass filters; the first stage filter was a sinc3 type and the second stage filter was a 22-tap filter. We used 95\% confidence ellipse (area), anterior-posterior average displacement (Ymean), and medial-lateral average displacement (Xmean) for the COP values.

\section{(5) Analyses}

Data were analyzed using SPSS ver. 18.0. The general characteristics of the subjects were analyzed by deriving averaged values and standard deviations. In order to examine differences in the TUG test, TWT, COP values, medial-lateral displacement, and anterior-posterior displacement within each group between prior to and 8 weeks after the experiment, a paired t-test was conducted. All significance levels to verify hypotheses were set at $\alpha=.05$.

\section{RESULTS}

1. Changes in Dynamic balance ability after the pilates exercise

There were significant changes in the results of the TUG test and TWT 8 weeks after the pilates exercise $(\mathrm{p}<.05)$ (Table 3).

Table 3. Time up go test (TUG) and Tandom Walk test (TWT) results (in seconds) before and after the pilates exercise

\begin{tabular}{cccc}
\hline variable & $\begin{array}{c}\text { Pre-exercise } \\
(\text { Mean } \pm \text { SD) }\end{array}$ & $\begin{array}{c}\text { Post-exercise } \\
(\text { Mean } \pm \text { SD) }\end{array}$ & $\mathrm{p}$ \\
\hline TUG $(\mathrm{sec})$ & $15.37 \pm 2.84$ & $13.27 \pm 3.47$ & $.01^{*}$ \\
TWT & $16.32 \pm 5.97$ & $12.54 \pm 1.97$ & $.00^{*}$ \\
\hline
\end{tabular}

$* \mathrm{p}<.05$

2. Changes in static balance ability after the pilates exercise

There were significant changes after the 8-week pilates exercise in the COP area and medial-lateral displacement $(\mathrm{p}<.05)$ (Table 4).

Table 4. COP area, medial-lateral displacement, and anterior-posterior displacement prior to and after the pilates exercise

\begin{tabular}{cccc}
\hline Variable & $\begin{array}{c}\text { Pre } \\
(\text { Mean } \pm \text { SD })\end{array}$ & $\begin{array}{c}\text { post } \\
(\text { Mean } \pm \text { SD })\end{array}$ & p \\
\hline Area $\left(\mathrm{mm}^{2}\right)$ & $213.84 \pm 197.74$ & $157.14 \pm 207.18$ & $.00^{*}$ \\
Xmean $(\mathrm{mm})$ & $5.53 \pm 11.10$ & $2.18 \pm 9.88$ & $.02^{*}$ \\
Ymean $(\mathrm{mm})$ & $8.75 \pm 10.97$ & $8.80 \pm 7.22$ & .98 \\
\hline *p $<.05$ & & & \\
Area, Center of & pressure area; Xmean, medial-lateral \\
displacement; Ymean, anterior-posterior displacement.
\end{tabular}

\section{DISCUSSION}

The purpose of this study was to examine the effects of pilates exercise on elderly people's static and dynamic 
balance abilities We found significant differences between the results of the TUG test and TWT. Pilates exercise is an effective exercise for postural symmetry, respiration control, abdominal muscle strength, spinal, pelvic, and trunk stability, muscle flexibility, joint mobility, and muscle strength improvement, positively influencing enhancement in balance(Latey, 2002).

Deep muscles composing the trunk include the transverse abdominis, multifidus, internal oblique, paraspinals, and pelvic floor. Such muscles support the lumbar spine and stabilize the trunk(Donald, 2009). Seok et al.(2013) reported that 6 -week pilates exercise significantly improved lumbar flexibility and muscle strength, and $\operatorname{Kim}(2010)$ also found that 12-week pilates exercise strengthened lumbar muscles, significantly increasing their stability. When lumbar muscle stability is enhanced, balance ability during postural maintenance or movement is improved (ShumwayCook, 2011). They also heighten dynamic stability of the body and can be strengthened through pilates(Akuthota and Nadler, 2004). These reasons explain the significant changes that occurred in the TWT results after the pilates exercise in our study.

The TUG test is an easy method to measure functional mobility; it can test functional movement in a small space without special equipment or training and is frequently used to measure dynamic balance(Jessup et al., 2003). The TUG time of normal adults without neurological damage is less than $10 \mathrm{sec}$ (Podsiadlo and Richardson, 1991), while the TUG time of normal males in their 60 s ranges from 8 to $13 \mathrm{sec}$ (Steffen et al., 2002). Podsiadlo and Richardson (1991) reported that when TUG time was $14 \mathrm{sec}$ or longer, the risk of a fall increased and when it was $30 \mathrm{sec}$ or longer, moving was not possible and therefore outdoor movement alone was impossible. Lee et al.(2010) applied a balance exercise program to elderly subjects with diabetic neuropathy $60 \mathrm{~min}$ per time, twice per week for 8 weeks and reported that TUG time significantly decreased after such training. Madureira et al.(2007) and Liu-Ambrose et al.(2008) also found that the TUG time of elderly people taking part in balance exercise decreased. As in previous studies, we found the TUG time of the group who exercised with pilates for 8 weeks significantly decreased, with a corresponding enhancement of the subjects' flexibility, balance, and coordination(Siqueira Rodrigues, 2010; Irez et al., 2011).

In the present study, there were significant changes in the COP area and medial-lateral displacement among the static balance ability elements after the pilates exercise. Yoon(2009) applied pliates exercise to subjects 36 times for 12 weeks, 60 min each time and reported an improvement in balance and postural alignment after the training. Park(2013) trained 20 elderly females on a total of eight pilates motions, three times per week for 12 weeks and reported significant improvement in muscle endurance, dynamic balance ability, and static balance ability. In the present study as well, static balance ability significantly increased, and this can be attributed to enhanced body balance, muscle strength, and flexibility of the abdominal and back muscle joints(Denise, 2002).

There are some limitations that need to be considered when interpreting the results of this study. The results cannot be generalized to all elderly people as the number of subjects was small and their diverse physical characteristics were not sufficiently taken into account. In addition, the present study did not include those with chronic disease and could not exclude the effect of elderly people's chronic degenerative physical characteristics. Therefore, future research to study the association between physical characteristics and functional levels of the elderly needs to include a larger number of subjects and to reflect their individual characteristics.

\section{CONCLUSIONS}

The pilates program was applied to 19 elderly subjects 
three times per week for 8 weeks. Changes in their dynamic balance ability (TUG test and TWT) and static balance ability (center of pressure area, medial-lateral displacement, and anterior-posterior displacement) were examined after pilates training. The TUG test and TWT results and the COP area and medial-lateral displacement results were significantly different after the pilates exercise program compared to those before the program began $(\mathrm{p}<.05)$.

\section{Acknowledgements}

Funding of this paper was provide by Namseoul University.

\section{References}

Akuthota V, Nadler SF. Core strengthening. Arch Phys Med Rehabil. 2004;85:S86-92.

Aladro-Gonzalvo AR, Machado-Díaz M, Moncada-Jiménez $\mathrm{J}$ et al. The effect of Pilates exercises on body composition: a systematic review. J Bodyw Mov Ther. 2012;16(1):109-14.

Anderson BD, Spector A. Introduction to Pilates-based rehabilitation. Orthop Phys Ther Clin Nor America 2000;9(3):395-410.

Carmeli E, Bar-Chad S, Lotan M et al. Five clinical tests to assess balance following ball exercises and treadmill training in adult persons with intellectual disability. J Gerontol A Biol Sci Med Sci. 2003;58(8):767-72.

Denise A. Pilates for every body. Daehan media co. 2002.

Donald AN. Kinesiology of the musculoskeletal system: Foundations for rehabilitation(2ed). Mosby, 2009.

Emery K, De Serres SJ, McMillan A et al. The effects of a Pilates training program on arm-trunk posture and movement. Clin Biomech. 2010;25(2):124-30.

Gauchard GC, Gangloff P, Jeandel C et al. Physical activity improves gaze and posture control in the elderly. Neurosci Res. 2003;45(4):409-17.

Gras LZ, Levangie PK, Goodwin-Segal M et al. A Comparison of Hip versus Ankle Exercises in Elders and the Influence on Balance and Gait. J Geriatr Phys Ther, 2004:27(2):39-46.

Irez $\mathrm{GB}$, Ozdemir RA, Evin R et al. Integrating pilates exercise into an exercise program for $65+$ year-old women to reduce falls. J Sports Sci Med. 2011;10(1):105-11.

Jessup JV, Horne C, Vishen RK et al. Effects of exercise on bone density, balance, and self-efficacy in older women. Biol Res Nurs. 2003;4(3):171-80.

Karlsson MK, Vonschewelov T, Karlsson C et al. Prevention of falls in the elderly: a review. Scand J Public Health. 2013;41(5):442-54.

Kim DY. Effect of 12 weeks pilates training on stability. J Kor Soc Rhythmic exer. 2010;3(1):53-8.

Kloubec JA. Pilates for improvement of muscle endurance, flexibility, balance, and posture. J Strength Cond Res. 2010;24(3):661-7.

Latey, PL. Modern pilates; the step by step, at home guide to stronger body. Allen \& Unwin. 2002;15-7.

Lee H, Rachel D. The influence of Pilates training on the ability to contract the Transversus Abdominis muscle in asymptomatic individuals. J Bodywork and Movement Therapies. 2005;9:52-7.

Lee KJ, Song CH, Shin SH et al. Effects of balance exercise program on balance, gait, and proprioception in older adults with diabetic neuropathy. J Kor Gerontological Soc. 2010;30(2):385-99.

Liu-Ambrose T, Donaldson MG, Ahamed Y et al. Otago home-based strength and balance retraining improves executive functioning in older fallers: a randomized controlled trial. J Am Geriatr Soc. 2008;56(10): 1821-30.

Madureira MM, Takayama L, Gallinaro AL et al. Balance training program is highly effective in improving functional status and reducing the risk of falls in 
elderly women with osteoporosis: a randomized controlled trial. Osteoporos Int. 2007;18(4):419-25.

Mallinson AI, Longridge NS. Increasing the usefulness of tandem walking evaluation. J Otolaryngol Head Neck Surg. 2008;37(6):860-4.

Noll DR. Management of falls and balance disorders in the elderly. J Am Osteopath Assoc. 2013;113(1):17-22.

Park CS. The effect of pilates exercise on the body composition and health fitness of senior women. Woosuk University Graduate School. Master's thesis.. 2013.

Park SS, Chung YJ, Kang HK. Effects of Participation in Pilates on Muscular Strength, Proprioception, and Balance of University Students Group. Kor Alliance for Health, Physical edu, Recreation, Dance. 2011; 50(1):235-242.

Podsiadlo D, Richardson S. The timed "Up \& Go": a test of basic functional mobility for frail elderly persons. J Am Geriatr Soc. 1991;39(2):142-8.

Queiroz BC, Cagliari MF, Amorim CF et al. Muscle activation during four Pilates core stability exercises in quadruped position. Arch Phys Med Rehabil. 2010; 91(1):86-92.

Shumway-Cook A, Woollacott M, Kerns KA et al. The effects of two types of cognitive tasks on postural stability in older adults with and without a history of falls. J Gerontol A Biol Sci Med Sci. 1997;52(4):M232-40. Shumway-Cook A, Woollacott MH. Motor Control: Translating Research into Clinical Practice(4th). LWW 2011.

Siqueira Rodrigues BG, Ali Cader S, Bento Torres NV et al. Pilates method in personal autonomy, static balance and quality of life of elderly females. J Bodyw Mov Ther. 2010;14(2):195-202.

Steffen TM, Hacker TA, Mollinger L. Age and gender-related test performance in community-dwelling elderly people: Six-Minute Walk Test, Berg Balance Scale, Timed Up \& Go Test, and gait speeds. Phys Ther. 2002;82(2):128-37.

Suk BK, Oh JW, Lee SJ et al. The Effect of Pilates and Taping on Flexibility and Muscle Strength of Low Back. Kor Soc Intergration Med. 2013;1(1):23-31.

Tideiksaar R. Falling in old age; Its pervention and treatment (2nd). New York, Springer. 1996.

Yoon HS. The Effect of pilates program for the development of posture and balance. Myongii University Graduate School. doctor's thesis. 2009. 